\title{
Cardiac magnetic resonance based deformation imaging: role of feature tracking in athletes with suspected arrhythmogenic right ventricular cardiomyopathy
}

\author{
Csilla Czimbalmos ${ }^{1} \cdot$ Ibolya Csecs $^{1} \cdot$ Zsofia Dohy $^{1} \cdot$ Attila Toth $^{1} \cdot$ Ferenc Imre Suhai ${ }^{1} \cdot$ Andreas Müssigbrodt $^{2}$. \\ Orsolya Kiss $^{1} \cdot$ Laszlo Geller $^{1} \cdot$ Bela Merkely ${ }^{1} \cdot$ Hajnalka Vago $^{1}{ }^{1}$
}

Received: 25 June 2018 / Accepted: 16 October 2018 / Published online: 31 October 2018

(c) The Author(s) 2018

\begin{abstract}
Both, arrhythmogenic right ventricular cardiomyopathy (ARVC) and regular training are associated with right ventricular (RV) remodelling. Cardiac magnetic resonance (CMR) is given an important role in the diagnosis of ARVC in current task force criteria (TFC), however, they contain no cut-off values for athletes. We aimed to confirm the added value of feature tracking and to provide new cut-off values to differentiate between ARVC and athlete's heart. Healthy athletes with training of minimal $15 \mathrm{~h}$ /week $(\mathrm{n}=34)$, patients with definite ARVC $(\mathrm{n}=34)$ and highly trained athletes with ARVC $(\mathrm{n}=8)$ were examined by CMR. Left and right ventricular volumes and masses were determined. Global right and left ventricular, and regional strain analysis for the RV free wall was performed using feature tracking on balanced steady-state free precession cine images. $94 \%$ of healthy athletes showed RV dilatation of the proposed TFC, $14.7 \%$ showed RV ejection fraction (RVEF) between $45-50 \%$, none of them had RVEF $<45 \%$. Although RVEF showed the highest accuracy in differentiating between athlete's heart and ARVC, only $37.5 \%$ of athletes with ARVC showed RVEF $<45 \%$. The only parameters falling in the pathological range (based on our established cut-off values: $>-25.6$ and $>-1.4$, respectively) in all athletes with ARVC were the strain and strain rate of the midventricular RV free wall. Establishing RVEF and RV strain analysis provides an important tool to distinguish ARVC from athlete's heart. CMR based regional strain and strain rate values may help to identify ARVC even in highly trained athletes with preserved RVEF.
\end{abstract}

Keywords Arrhythmogenic right ventricular cardiomyopathy · Athlete's heart · Cardiac magnetic resonance imaging · Feature tracking

Bela Merkely and Hajnalka Vago have contributed equally in this work.

Hajnalka Vago

vagoha@gmail.com

Csilla Czimbalmos

csilla.czimbalmos@gmail.com

Ibolya Csecs

ibolyacsecs@gmail.com

Zsofia Dohy

dohyzsofi@gmail.com

Attila Toth

atoth@atoth.sote.hu

Ferenc Imre Suhai

suhaiimi987@gmail.com

Andreas Müssigbrodt

andreas.muessigbrodt@gmail.com
Orsolya Kiss

dr.orsolya.kiss@gmail.com

Laszlo Geller

laszlo.geller@gmail.com

Bela Merkely

merkely.bela@gmail.com

1 Heart and Vascular Center, Semmelweis University, Budapest, Hungary

2 Department of Electrophysiology, Heart Centre, University of Leipzig, Leipzig, Germany 


\section{Introduction}

Prolonged endurance exercise may lead to pronounced morphological changes of the right ventricle [1]. However, certain exercise induced alterations seem to be a benign consequence of athletic performance, occasionally observed overlap between arrhythmogenic right ventricular cardiomyopathy (ARVC) and physiological right ventricular adaptation may lead to clinical challenges. As in some European countries up to $20 \%$ of sudden cardiac deaths (SCD) in young individuals and athletes may be caused by ARVC [2, 3], thus differentiation between physiological and pathological RV remodelling is essential as correct diagnosis may prevent SCD. Moreover, misdiagnosis of ARVC may have serious health- and career-related consequences.

Overlapping electrical and structural features of athlete's heart and ARVC — such as right bundle branch block, T-wave inversion in precordial leads, elevated RV enddiastolic volume (RVEDVi) or slightly decreased EF-may cause diagnostic difficulties. Current TFC require as a major criterion regional RV akinesia or dyskinesia or dyssynchronous $\mathrm{RV}$ contraction and $\mathrm{RVEDVi} \geq 110 \mathrm{ml} / \mathrm{m}^{2}$ (male) or $\geq 100 \mathrm{ml} / \mathrm{m}^{2}$ (female) or RV ejection fraction $\leq 40 \%$. As a minor criterion regional $\mathrm{RV}$ akinesia or dyskinesia or dyssynchronous $\mathrm{RV}$ contraction and a ratio of $\mathrm{RVEDVi} \geq 100$ to $<110 \mathrm{ml} / \mathrm{m}^{2}$ (male) or $\geq 90$ to $<100 \mathrm{ml} / \mathrm{m}^{2}$ (female) or RV ejection fraction $>40 \%$ to $\leq 45 \%$ is required [4]. Thus, morphological features of ARVC require wall motion abnormalities and increased RV volume or decreased RV ejection fraction. As the diagnosis of wall motion abnormalities is based on individual subjective judgement and current TFC contain no athlete-specific criteria adapted for the objective parameters RVEDVi and RVEF [4], misdiagnosis of ARVC in healthy athletes may occur frequently. Therefore, improved cut-off values for CMR parameters differentiating ARVC and athlete's heart are needed.

Tissue tracking technology such as speckle tracking echocardiography and feature tracking CMR recently have become a subject of great interest for clinicians managing patients with ARVC. Feature tracking technique allows us to estimate myocardial strain, a measure of deformation using balanced steady-state free precession (bSSFP) cine images. Recent literature data imply, that CMR based deformation imaging using feature tracking technology may have an important added value in the diagnostic workup of ARVC patients [5-8], although no data regarding athletes' normal $\mathrm{RV}$ values are available. To the best of our knowledge, this is the first study to compare healthy athletes' and ARVC patients' strain parameters using feature tracking.

Connection between sport activity and ARVC is an intensively studied topic. It is a proven fact, that high intensity exercise is a strong independent marker of lifethreatening arrhythmias [9] and exercise dose reduction results in decreased risk of ventricular arrhythmias [10], therefore competitive sport is discouraged in ARVC patients [11]. Although CMR is the gold standard noninvasive method to measure RV volumes and function, there are only few studies investigating the role of athletic performance using CMR [12-14]. Not surprisingly, competitive athletes have significantly larger RV volumes than recreational athletes or sedentary patients. In terms of RVEF literature data are contradictory. Saberniak et al. showed that athletes have reduced ejection fraction compared to non-athletes, suggesting that sport accelerates ventricular dysfunction in ARVC, while Ruwald et al. could not prove any difference in EF between competitive athletes, recreational athletes and inactive patients. Unfortunately these studies aimed to analyse only RV volumes and ejection fraction, more detailed CMR characteristics (including LGE or RV deformation imaging) of competitive athletes are reported only in case reports, or series [15-17].

Our goal was to compare conventional left and right ventricular parameters of healthy athletes with non-athletic ARVC patients, and to investigate clinical and detailed CMR characteristics of active highly trained athletes with ARVC. We tested the diagnostic accuracy of TF CMR criteria regarding RVEDVi and RVEF, and we tested whether global or regional strain analysis could improve the diagnostic value of CMR in this special patient population.

\section{Materials and methods}

\section{Study participants}

This study was conducted between 2010 and 2017. ARVC patients with definite diagnosis based on the revised Task Force criteria were consecutively enrolled $(n=34)$. Highly trained healthy athletes with a minimum of $15 \mathrm{~h}$ of training per week for at least 5 years performing sports with high dynamic and static components [18] were recruited $(n=34)$. Highly trained athletes in competition or training period with definite ARVC were also enrolled $(n=8)$. Ethical approval was obtained from the Central Ethics Committee of Hungary and has been performed in accordance with the ethical standards laid down in the 1964 Declaration of Helsinki and its later amendments. All subjects gave their informed consent prior to their inclusion in the study.

\section{CMR examination}

CMR examinations were conducted on a 1.5 T MR scanner (Achieva, Philips Medical Systems) with a 5-channel 
cardiac coil. Locaizing scans were followed by breath-hold cine imaging in transversal planes. Retrospectively-gated, balanced steady-state free precession (bSSFP) segmented cine images were acquired in 2-chamber, 4-chamber and LV outflow tract views. Short-axis images with full coverage of the left and right ventricle, and RV outflow tract images were obtained with a temporal resolution $\leq 40 \mathrm{~ms}$, with a mean echo time/repetition time/flip angle: $1.35 \mathrm{~ms} / 2.7 \mathrm{~ms} / 60^{\circ}$, respectively. 30 phases per cardiac cycle were acquired with one or two slices per 10-14 s breath-hold depending on the patients/individuals breath-hold capacity. Image domain based parallel imaging (SENSE) was used in case of shortaxis movies (acceleration factor 2.0). Spatial resolution regardless of the field-of view $(350 \mathrm{~mm}$ on average adapted to body size) with a mean acquisition pixel size of $1.6 \mathrm{~mm}$ $\times 1.6 \mathrm{~mm}$, slice thickness was $8 \mathrm{~mm}$ with no interslice gap.

Late gadolinium enhancement (LGE) imaging was performed if patients gave their informed consent $(82.4 \%$ of healthy athletes and $94.1 \%$ of ARVC patients, $100 \%$ of athletes with ARVC). During an inspiratory breath-hold, a bolus of gadobutrol $(0.15 \mathrm{mmol} / \mathrm{kg})$ was injected at a rate of $2-3 \mathrm{ml} / \mathrm{s}$ through antecubital intravenous line. Contrastenhanced images were acquired using a segmented inversion recovery sequence with additional phase sensitive reconstructions in long- and short-axis views (slice thickness $8 \mathrm{~mm}$ with no interslice gap, mean echo time 2.2/repetition time 4.6/flip angle: 15) 10-20 min after contrast administration. Parallel imaging is not utilized in LGE images. The inversion-time was adjusted to provide optimal suppression of apparent normal myocardium.

\section{Image analysis}

All images were evaluated with Medis Suite (QMass and QStrain) Software (Medis Medical Imaging Systems, version 3.0, Leiden, The Netherlands). Endocardial and epicardial contour detection was performed by a blinded expert observer manually on short axis cine images in end-systolic and end-diastolic phases. Quantification of the left and right ventricular ejection fraction (LVEF, RVEF), end-systolic volume (LVESV, RVESV), end-diastolic volume (LVEDV, RVEDV), stroke volume (LVSV, RVSV) and myocardial mass (LVM, RVM) were performed. Left and right ventricular volumes and masses were standardized to body surface area (BSA)-LVESVi, RVESVi, LVEDVi, RVEDVi, LVSVi, RVSVi, LVMi and RVMi. Regional right ventricular akinesis, dyskinesis, dyssynchrony were qualitatively assessed. Global LV and RV strain analysis was performed based on cine images after manual contouring of the endocardial borders. Additionally, regional strain analysis for the right ventricular free wall was performed based on RV endocardial contours on $4 \mathrm{CH}$-view, peak systolic longitudinal strain and strain rate values of the basal, midventricular and apical free wall were established. Average and minimal values of the measured regional strain and strain rate values were also determined.

\section{Statistical analysis}

Continuous variables were reported as mean and standard deviation, and categorical variables as frequency and percentages. Between-group comparisons were performed with the unpaired Student's $t$ test, or Mann-Whitney U-test where appropriate. Diagnostic accuracy of CMR parameters was evaluated using receiver operating characteristic (ROC) curve analysis with $\geq 4$ Task Force Score (major criteria $=2$ points, minor criteria $=1$ point ). For area under the curve (AUC), a value of 0.9-1.0 was considered excellent, $0.75-0.9$ good, $0.6-0.75$ moderate and $0.5-0.6$ poor. Optimal cut-off values for ARVC patient vs. athlete classification were derived from ROC curves coordinates by maximizing the proportion of subjects correctly classified. A p-value of $\leq 0.05$ was considered statistically significant. Statistical analysis was performed with MedCalc software (version 17.9).

\section{Results}

\section{Baseline characteristics}

\section{Healthy athletes}

Thirty-four highly trained healthy athletes with no signs of cardiovascular disease and with a minimum of $15 \mathrm{~h}$ of training per week for at least 5 years performing sports with high dynamic and static components $(31.8 \pm 6.1$ years, 22 male, 18.6 \pm 2.2 training $\mathrm{h} /$ week) were recruited, including canoe and kayakers $(n=17)$, rowers $(n=5)$, boxers $(n=5)$, triathletes $(n=4)$ and cyclists $(n=3)$. None of the healthy athletes had positive family history of sudden cardiac death or ARVC, all of them were asymptomatic. None of the healthy athletes had any ECG abnormality suggesting structural heart disease, none of them showed $\mathrm{T}$-wave inversion in more than 1 continuous leads, Q wave inversion or ST-depression. $81 \%$ of athletes showed J-point elevation, $19 \%$ Sokolow or Cornell index positivity for left ventricular hypertrophy. None of them showed regional right ventricular wall motion abnormality or late gadolinium enhancement (LGE). RVEDVi was in the proposed range of the major TFC ( $>110 \mathrm{ml} / \mathrm{m}^{2}$ in males, $>100 \mathrm{ml} / \mathrm{m}^{2}$ in females) in all healthy male athletes and $83.3 \%$ of healthy female athletes. RVEDVi of the remaining female athletes were in the proposed range of the minor TFC ( $>90 \mathrm{ml} / \mathrm{m}^{2}$ in females). None of the athletes showed RVEF $\leq 45 \%$, RVEF between 
45 and $50 \%$ was observed in 5 cases (14.7\%, three male and two female athletes).

\section{ARVC patients}

Diagnosis of ARVC was based on current TFC [4]. Thirty-four non-athlete ARVC patients were enrolled (40.5 \pm 13.4 years, 22 male). Positive family history for sudden cardiac death or ARVC was present in $18 \%$ of the ARVC patients, 59\% had recorded sustained ventricular tachycardia (VT) or ventricular fibrillation (VF), and aborted sudden cardiac death was reported in $12 \%$. Average Task Force score $($ major $=2$ points, minor $=1$ point $)$ was 4.9 points. Biventricular involvement was observed in 71\%. LGE was present in $69 \%$, in 14 patients only in the $\mathrm{LV}$, in two patients only in the RV, and 6 patients demonstrated biventricular LGE (Fig. 1).

\section{Athletes with ARVC}

In eight additional active athletes $(18.9 \pm 4.6$ training $\mathrm{h} /$ week, triathletes $n=3$, cyclists $n=2$, swimmers $n=2$, football player $n=1$ ) the comprehensive investigation including resting ECG, ambulatory ECG monitoring, echocardiography, CMR and patient history confirmed the diagnosis (Fig. 2). In three cases, CMR examination was repeated after training cessation for 2-3 months. Successful deconditioning effect was observed on LV values (LVEDVi: $127.4 \pm 5.4 \mathrm{ml} / \mathrm{m}^{2}$ vs. $109 \pm 10.6 \mathrm{ml} / \mathrm{m}^{2}$; LVMi: $93.4 \pm 16.7$ vs. $73.5 \pm 9.4$ ), but only blunted deconditioning effect was observed on RV values, RVEDVi remained in the pathological range $\left(169.7 \pm 10.5 \mathrm{ml} / \mathrm{m}^{2}\right.$ vs. $\left.137.3 \pm 17.1 \mathrm{ml} / \mathrm{m}^{2}\right)$. Four athletes had documented sustained VT or VF, and aborted sudden cardiac death was reported in two cases. None of them had positive family history for ARVC or SCD. Two athletes did not fulfil any repolarization or depolarization criteria, TWI in lead v1-v2 and in v1-v3 leads was observed in one and four athletes, respectively.
Repolarization or depolarization criteria

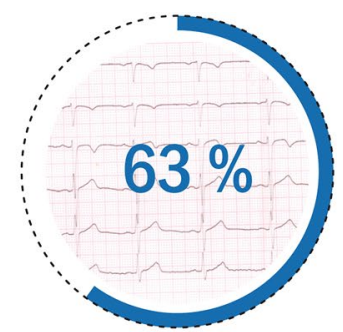

Sustained ventricular tachycardia or ventricular fibrillation

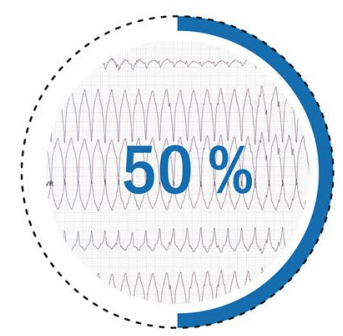

Fibrosis

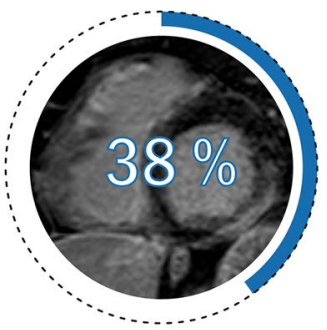

Longitudinal strain and strain rate of the midventricular RV free wall in the pathological range

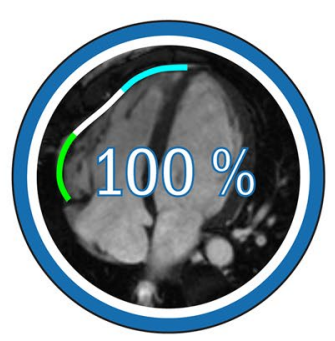

Fig. 2 Clinical characteristics of athletes with ARVC including pathological ECG findings, arrhythmias and myocardial fibrosis. Midventricular RV longitudinal strain and strain rate were in the pathological range based on our cut-off values in all of the athletes with ARVC

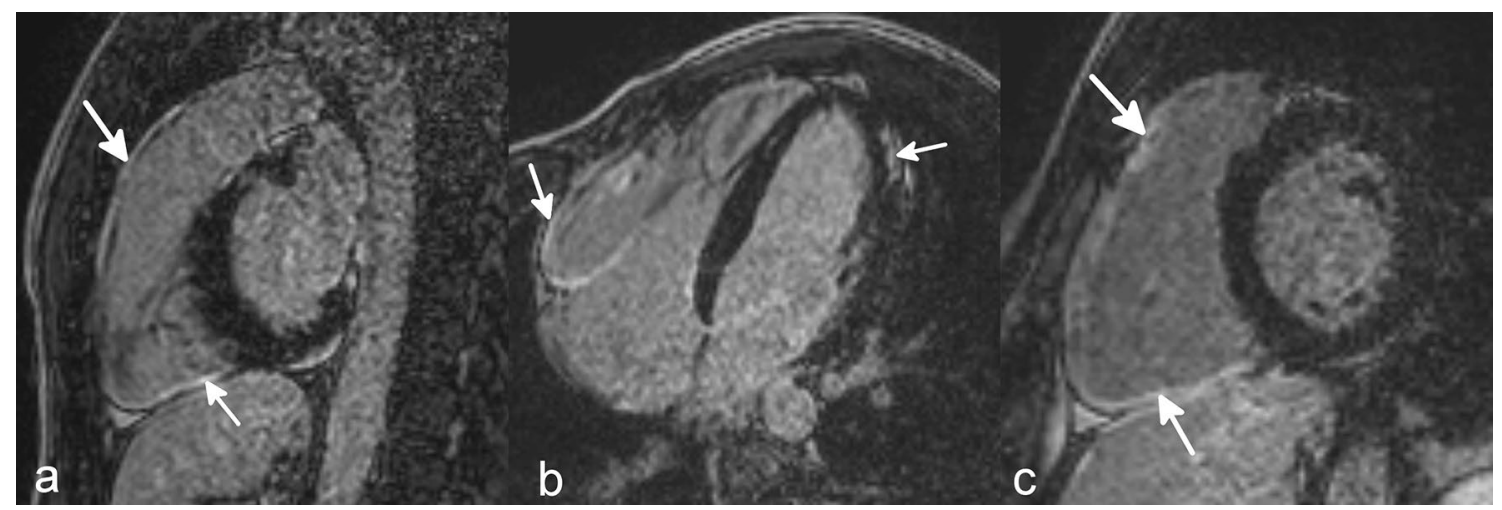

Fig. 1 LGE images of an athlete with biventricular ARVC 
Table 1 Baseline characteristics and task force criteria of healthy athletes, sedentary ARVC patients and athletes with ARVC

\begin{tabular}{llll}
\hline & Athletes $(\mathrm{n}=34)$ & ARVC $(\mathrm{n}=34)$ & Athletes with \\
& & & ARVC $(\mathrm{n}=8)$ \\
\hline Task force criteria: & & & \\
Global or regional dysfunction and structural alterations & & $8 / 8$ \\
Major & $0 / 34$ & $30 / 34$ & $0 / 8$ \\
Minor & $0 / 34$ & $4 / 34$ & - \\
Tissue characterization of wall & & - \\
Major & - & $2 / 3$ & $4 / 8$ \\
Minor & - & $1 / 3$ & $1 / 8$ \\
Repolarization abnormalities & & & $2 / 8$ \\
Major & $0 / 34$ & $22 / 34$ & $2 / 8$ \\
Minor & $0 / 34$ & $1 / 34$ & $4 / 8$ \\
Depolarization abnormalities & & & $3 / 8$ \\
Major & $0 / 34$ & $2 / 34$ & \\
Minor & $0 / 34$ & $6 / 34$ & $0 / 8$ \\
Arrhythmias & & & $0 / 8$ \\
Major & $0 / 34$ & $7 / 34$ & $5.4 \pm 1.2$ \\
Minor & $0 / 34$ & $21 / 34$ & \\
Family history & & $3 / 33$ & \\
Major & $0 / 34$ & $3 / 33$ & \\
Minor & $0 / 34$ & $4.9 \pm 0.7$ & \\
TF points & $0.0 \pm 0.0$ & & \\
\hline
\end{tabular}

TF points: major $=2$, minor $=1$ points
One patient had complete right bundle branch block. Epsilon wave was observed in 3 patients. Average Task Force score was 5.4 points (Table 1). Biventricular involvement was confirmed in three patients (defined by left ventricular LGE and/or LVEF < 50). Three patients showed LGE: two of them biventricular and one solely left ventricular LGE. All athletes with definite diagnosis of ARVC were disqualified from competitive sport.

\section{Characteristics of patient and subject groups- comparison of CMR parameters between healthy athletes and ARVC patients}

Healthy athletes showed higher LVEDVi, LVSVi, LVMi, RVSVi and RVMi than non-athlete ARVC patients, no significant difference was found between athletes and non-athlete ARVC patients regarding the RVEDVi. Both RVEF and LVEF were significantly lower in ARVC patients compared to healthy athletes (Table 2).

RV global longitudinal strain (RV GLS) was decreased in the ARVC group compared to athletes. Regional longitudinal strain and strain rates of the RV free wall are presented in Table 3. RV mid strain, RV mid strain rate, and average and minimal values of the measured regional strain and strain rate values showed significant difference between the two groups (Table 3).

\section{Diagnostic accuracy of CMR parameters and feature tracking based deformation imaging to differentiate ARVC and athlete's heart}

Establishing AUC values for the CMR parameters RVEF showed good accuracy (AUC $=0.830)$, whereas RVEDVi failed as a discriminator between ARVC and athlete's heart (AUC $=0.599$ ). Cut-off value for $\mathrm{RVEF} \leq 45.8$ discriminates between ARVC and athlete's heart with a sensitivity of $68 \%$ and a specificity of $100 \%$. RV mid strain, average and minimum of the measured regional strain values demonstrated good discrimination between athlete's heart and ARVC. We investigated whether establishing gender-specific cut-off values may influence the diagnostic accuracy, but comparing male and female ROC curves for CMR parameters with the highest diagnostic accuracy (RVEF, RV mid strain, RV average strain, RV min strain) showed no significant difference. These results suggests that gender-specific differences regarding these parameters are negligible, so we present cutoff values for both males and females. Cut-off values for global and regional strain values are presented in Table 4.

We tested the established cut-off values for CMR parameters in the group of highly trained athletes with diagnosed ARVC. Applying the established cut-off values, RVEF was in the pathological range in only 3 athletes with ARVC. Half of the athletes with ARVC showed normal RV GLS. Regional longitudinal strain and strain rate of the RV mid 
Table 2 Baseline characteristics and conventional left and right ventricular CMR parameters in healthy athletes, ARVC patients and athletes with ARVC

\begin{tabular}{|c|c|c|c|}
\hline & $\begin{array}{l}\text { Athletes }(\mathrm{n}=34) \\
\text { Mean } \pm \text { SD }\end{array}$ & $\begin{array}{l}\operatorname{ARVC}(n=34) \\
\text { Mean } \pm S D\end{array}$ & $\begin{array}{l}\text { Athletes with } \\
\text { ARVC }(n=8) \\
\text { Mean } \pm \text { SD }\end{array}$ \\
\hline Age (years) & $\begin{array}{l}31.8 \pm 7.7 \\
{[28.7-34.0]}\end{array}$ & $\begin{array}{l}40.5 \pm 16.3^{*} \\
{[32.5-44.3]}\end{array}$ & $\begin{array}{l}27.6 \pm 3.3 \\
{[24.4-30.7]}\end{array}$ \\
\hline $\operatorname{BSA}\left(\mathrm{m}^{2}\right)$ & $\begin{array}{l}1.94 \pm 0.19 \\
{[1.87-2.06]}\end{array}$ & $\begin{array}{l}1.88 \pm 0.21 \\
{[1.78-2.00]}\end{array}$ & $\begin{array}{l}1.86 \pm 0.13 \\
{[1.70-2.02]}\end{array}$ \\
\hline Male (\%) & 65 & 65 & 87.5 \\
\hline Heart rate (bpm) & $\begin{array}{l}55.0 \pm 7.6 \\
{[50.0-60.0]}\end{array}$ & $\begin{array}{l}63.0 \pm 7.4 * * * \\
{[61.0-66.2]}\end{array}$ & $\begin{array}{l}58.5 \pm 8.8 \\
{[46.0-69.1]}\end{array}$ \\
\hline LVEF (\%) & $\begin{array}{l}57.6 \pm 4.7 \\
{[54.6-60.5]}\end{array}$ & $\begin{array}{l}52.0 \pm 11.2 * \\
{[46.9-57.8]}\end{array}$ & $\begin{array}{l}60.1 \pm 3.1 \\
{[56.0-64.5]}\end{array}$ \\
\hline LVESVi $\left(\mathrm{ml} / \mathrm{m}^{2}\right)$ & $\begin{array}{l}50.3 \pm 10.9 \\
{[43.2-53.4]}\end{array}$ & $\begin{array}{l}50.9 \pm 20.0 \\
{[40.0-50.9]}\end{array}$ & $\begin{array}{l}50.2 \pm 8.3 \\
{[41.0-61.8]}\end{array}$ \\
\hline LVEDVi $\left(\mathrm{ml} / \mathrm{m}^{2}\right)$ & $\begin{array}{l}117.8 \pm 17.3 \\
{[107.8-122.6]}\end{array}$ & $\begin{array}{l}107.2 \pm 22.5^{*} \\
{[93.5-117.0]}\end{array}$ & $\begin{array}{l}121.1 \pm 17.4 \\
{[95.1-142.2]}\end{array}$ \\
\hline $\operatorname{LVSVi}\left(\mathrm{ml} / \mathrm{m}^{2}\right)$ & $\begin{array}{l}67.6 \pm 9.4 \\
{[63.4-71.0]}\end{array}$ & $\begin{array}{l}54.0 \pm 13.1^{* * *} \\
{[50.1-58.7]}\end{array}$ & $\begin{array}{l}72.6 \pm 10.9 \\
{[60.5-83.7]}\end{array}$ \\
\hline LVMi (g/m²) & $\begin{array}{l}82.9 \pm 16.1 \\
{[76.2-89.0]}\end{array}$ & $\begin{array}{l}58.2 \pm 12.8^{* * * *} \\
{[51.1-61.4]}\end{array}$ & $\begin{array}{l}87.2 \pm 16.3 \\
{[68.7-109.8]}\end{array}$ \\
\hline RVEF (\%) & $\begin{array}{l}55.7 \pm 4.6 \\
{[54.2-57.3]}\end{array}$ & $\begin{array}{l}40.5 \pm 13.6^{* * *} \\
{[34.5-46.6]}\end{array}$ & $\begin{array}{l}47.5 \pm 3.8 \\
{[42.4-52.2]}\end{array}$ \\
\hline $\operatorname{RVESVi~}\left(\mathrm{ml} / \mathrm{m}^{2}\right)$ & $\begin{array}{l}55.6 \pm 11.9 \\
{[49.0-56.2]}\end{array}$ & $\begin{array}{l}88.3 \pm 45.1^{* * *} \\
{[62.4-89.4]}\end{array}$ & $\begin{array}{l}76.2 \pm 10.8 \\
{[62.7-97.4]}\end{array}$ \\
\hline $\begin{array}{l}\text { RVEDVi (ml/ } \\
\mathrm{m}^{2} \text { ) }\end{array}$ & $\begin{array}{l}123.6 \pm 17.0 \\
{[111.7-130.4]}\end{array}$ & $\begin{array}{l}142.7 \pm 47.5 \\
{[117.4-138.5]}\end{array}$ & $\begin{array}{l}146.1 \pm 25.7 \\
{[114.0-179.0]}\end{array}$ \\
\hline $\operatorname{RVSVi}\left(\mathrm{ml} / \mathrm{m}^{2}\right)$ & $\begin{array}{l}68.6 \pm 9.1 \\
{[64.0-72.7]}\end{array}$ & $\begin{array}{l}52.7 \pm 17.5 * * * \\
{[50.7-63.8]}\end{array}$ & $\begin{array}{l}70.0 \pm 15.1 \\
{[49.5-89.2]}\end{array}$ \\
\hline $\operatorname{RVMi}\left(\mathrm{g} / \mathrm{m}^{2}\right)$ & $\begin{array}{l}21.8 \pm 6.2 \\
{[18.1-25.2]}\end{array}$ & $\begin{array}{l}18.7 \pm 4.8 \\
{[14.7-20.4]}\end{array}$ & $\begin{array}{l}22.3 \pm 2.3 \\
{[19.8-24.4]}\end{array}$ \\
\hline
\end{tabular}

$B S A$ body surface area, $L V$ left ventricular, $R V$ right ventricular, $E F$ ejection fraction, $E S V i$ end-systolic volume index, $E D V i$ end-diastolic volume index, $S V i$ stroke volume index, $M i$ mass index

Values are expressed in mean \pm SD [95\% Confidence Interval]

$* \mathrm{p}<0.05 ; * * \mathrm{p}<0.01 ; * * * \mathrm{p}<0.001$, Significant difference between sedentary ARVC patients and healthy athletes

free wall were in the pathological range among all 8 athletes with ARVC (Fig. 3).

\section{Discussion}

Highly trained athletes participating in our study reached the major Task Force criteria on RV dilatation in almost $95 \%$. Based on these findings, RVEDVi failed as a discriminator, highlighting the difficulties of differentiation between ARVC and athlete's heart using the modified Task Force criteria. Although none of the athletes in this population showed RVEF under $45 \%$, previous CMR studies regarding reference $\mathrm{RV}$ values of athletes showed that RVEF between 40 and $45 \%$ could be observed in $5 \%$ of elite athletes, and pronounced RV dilatation is a typical feature in healthy athletes, even with only moderate training $[19,20]$.

Although CMR is the gold standard method to evaluate $\mathrm{RV}$ function and volumes, subjective assessment of right ventricular wall thinning and wall motion abnormalities in the clinical routine represents the Achilles' heel of CMR. Deformation imaging using feature tracking and novel methods such as ventricular shape analysis [21] may have an important added value in the objective assessment of right ventricular wall motion abnormalities. Based on the expert consensus document of the European Association of Cardiovascular Imaging (EACVI) regarding multi-modality imaging in arrhythmogenic right ventricular cardiomyopathy, deformation strain imaging is recommended in patients with suspected ARVC [22]. RV deformation imaging using twodimensional speckle tracking echocardiography, although currently available, is still challenging [23]. Based on recent data, global and regional right ventricular strain values of overt ARVC patients are decreased compared to healthy control subjects [5-8]. Moreover, multisoftware feasibility study of Bourfiss et al. proved excellent intra- and inter-observer reproducibility for the right ventricular regional strain values established using Medis QStrain software [5].

One advantage of CMR based strain analysis using feature tracking is the opportunity for retrospective analysis because no additional image acquisition is required. CMR based strain analysis moreover provides better tissue contrast and superior definition of the endocardial layer compared to speckle-tracking echocardiography, on the other hand speckle-tracking echocardiography has better spatial and temporal resolution. Average temporal and spatial resolutions expected from CMR-FT are: $25-35$ phases/cardiac cycle depending on heart rate (eg, 30-40 ms at a heart rate of $60 \mathrm{bpm}$ ) and $1-2 \times 1-2 \mathrm{~mm}$ in plane resolution with a slice thickness of 6-8 mm [24]. Technical improvements in the future may further optimize spatial and temporal resolution contributing to more precise strain analysis.

Although several echocardiographic studies have investigated the morphologic right ventricular adaptation of elite athletes [25], limited published data are available about CMR derived upper normal limit or cut-off values to differentiate athlete's heart and ARVC [14, 19, 20]. This is the first study to provide strain values on healthy athletes using feature tracking and compare it to ARVC patients' strain parameters.

Because of the pronounced RV adaptation observed in healthy highly trained athletes, diagnosing ARVC in elite athletes is more challenging than in sedentary individuals. Our findings imply that the phenotype of sedentary and athletic ARVC patients differ. We are the first to report detailed functional and morphological characteristics, and CMR based strain values of an athlete cohort with definite ARVC in training or competition period. According to 
Table 3 Global and regional strain and strain rate values of healthy athletes, ARVC patients and athletes with ARVC

\begin{tabular}{|c|c|c|c|}
\hline & $\begin{array}{l}\text { Athletes }(\mathrm{n}=34) \\
\text { Mean } \pm \text { SD }\end{array}$ & $\begin{array}{l}\text { ARVC }(n=34) \\
\text { Mean } \pm \text { SD }\end{array}$ & $\begin{array}{l}\text { Athletes with ARVC }(\mathrm{n}=8) \\
\text { Mean } \pm \text { SD }\end{array}$ \\
\hline \multicolumn{4}{|c|}{ Global left and right ventricular strain } \\
\hline LV GLS & $\begin{array}{l}-22.0 \pm 3.4 \\
{[-23.4 \text { to }-20.6]}\end{array}$ & $\begin{array}{l}-20.4 \pm 5.0 \\
{[-22.5 \text { to }-18.2]}\end{array}$ & $\begin{array}{l}-24.9 \pm 1.4 \\
{[-27.6 \text { to }-23.2]}\end{array}$ \\
\hline LV GCS & $\begin{array}{l}-30.5 \pm 6.0 \\
{[-32.5 \text { to }-27.1]}\end{array}$ & $\begin{array}{l}-26.3 \pm 7.8^{*} \\
{[-30.9 \text { to }-21.9]}\end{array}$ & $\begin{array}{l}-35.6 \pm 5.7 \\
{[-41.4 \text { to }-29.3]}\end{array}$ \\
\hline LV GRS & $\begin{array}{l}57.6 \pm 14.5 \\
{[49.3-58.5]}\end{array}$ & $\begin{array}{l}49.8 \pm 49.9 \\
{[40.7-58.3]}\end{array}$ & $\begin{array}{l}71.4 \pm 11.2 \\
{[58.0-87.2]}\end{array}$ \\
\hline RV GLS & $\begin{array}{l}-25.6 \pm 3.9 \\
{[-27.7 \text { to }-23.7]}\end{array}$ & $\begin{array}{l}-20.4 \pm 7.6^{* *} \\
{[-24.1 \text { to }-16.7]}\end{array}$ & $\begin{array}{l}-21.3 \pm 3.9 \\
{[-26.0 \text { to }-17.0]}\end{array}$ \\
\hline \multicolumn{4}{|c|}{ Regional longitudinal strain and strain rate values of the RV free wall } \\
\hline RV basal strain & $\begin{array}{l}-34.5 \pm 8.6 \\
{[-39.3 \text { to }-32.1]}\end{array}$ & $\begin{array}{l}-30.9 \pm 11.8 \\
{[-35.1 \text { to }-24.6]}\end{array}$ & $\begin{array}{l}-35.6 \pm 8.3 \\
{[-43.7 \text { to }-28.7]}\end{array}$ \\
\hline RV mid strain & $\begin{array}{l}-31.5 \pm 10.2 \\
{[-36.4 \text { to }-27.8]}\end{array}$ & $\begin{array}{l}-20.0 \pm 13.4 * * * \\
{[-23.4 \text { to }-12.0]}\end{array}$ & $\begin{array}{l}-21.5 \pm 4.9 \\
{[-25.3 \text { to }-14.6]}\end{array}$ \\
\hline RV apical strain & $\begin{array}{l}-30.9 \pm 8.0 \\
{[-35.8 \text { to }-27.4]}\end{array}$ & $\begin{array}{l}-24.6 \pm 11.6^{* *} \\
{[-28.2 \text { to }-19.6]}\end{array}$ & $\begin{array}{l}-19.7 \pm 11.1 \\
{[-29.1 \text { to }-8.2]}\end{array}$ \\
\hline RV average strain & $\begin{array}{l}-32.3 \pm 5.0 \\
{[-34.1 \text { to }-31.2]}\end{array}$ & $\begin{array}{l}-25.1 \pm 9.3 * * \\
{[-27.4 \text { to }-22.7]}\end{array}$ & $\begin{array}{l}-25.6 \pm 3.0 \\
{[-29.7 \text { to }-23.2]}\end{array}$ \\
\hline $\mathrm{RV}$ min strain & $\begin{array}{l}-24.0 \pm 7.2 \\
{[-27.4 \text { to }-22.7]}\end{array}$ & $\begin{array}{l}-15.2 \pm 9.0 * * * \\
{[-17.1 \text { to }-10.4]}\end{array}$ & $\begin{array}{l}-15.4 \pm 7.1 \\
{[-23.8 \text { to }-8.2]}\end{array}$ \\
\hline RV basal strain rate & $\begin{array}{l}-1.74 \pm 0.59 \\
{[-2.00 \text { to }-1.40]}\end{array}$ & $\begin{array}{l}-1.52 \pm 0.97 * \\
{[-1.70 \text { to }-0.90]}\end{array}$ & $\begin{array}{l}-1.61 \pm 0.63 \\
{[-2.40 \text { to }-0.94]}\end{array}$ \\
\hline $\mathrm{RV}$ mid strain rate & $\begin{array}{l}-1.37 \pm 0.56 \\
{[-1.70 \text { to }-1.08]}\end{array}$ & $\begin{array}{l}-1.04 \pm 0.68^{* *} \\
{[-1.20 \text { to }-0.70]}\end{array}$ & $\begin{array}{l}-1.05 \pm 0.22 \\
{[-1.22 \text { to }-0.78]}\end{array}$ \\
\hline RV apical strain rate & $\begin{array}{l}-1.33 \pm 0.40 \\
{[-1.50 \text { to }-1.10]}\end{array}$ & $\begin{array}{l}-1.17 \pm 0.56 \\
{[-1.32 \text { to }-0.80]}\end{array}$ & $\begin{array}{l}-0.96 \pm 0.34 \\
{[-1.32 \text { to }-0.71]}\end{array}$ \\
\hline $\mathrm{RV}$ average strain rate & $\begin{array}{l}-1.48 \pm 0.38 \\
{[-1.53 \text { to }-1.33]}\end{array}$ & $\begin{array}{l}-1.24 \pm 0.59^{*} \\
{[-1.43 \text { to }-0.86]}\end{array}$ & $\begin{array}{l}-1.21 \pm 0.28 \\
{[-1.49 \text { to }-0.92]}\end{array}$ \\
\hline $\mathrm{RV}$ min strain rate & $\begin{array}{l}-1.09 \pm 0.31 \\
{[-1.20 \text { to }-0.90]}\end{array}$ & $\begin{array}{l}-0.79 \pm 0.32 * * \\
{[-0.92 \text { to }-0.60]}\end{array}$ & $\begin{array}{l}-0.80 \pm 0.24 \\
{[-1.02 \text { to }-0.62]}\end{array}$ \\
\hline
\end{tabular}

Values are expressed in mean \pm SD [95\% Confidence Interval]

$G L S$ global longitudinal strain, GCS global circumferential strain, GRS global regional strain ${ }^{*} \mathrm{p}<0.05 ; * * \mathrm{p}<0.01 ; * * * \mathrm{p}<0.001$, Significant difference between sedentary ARVC patients and healthy athletes literature data ejection fraction may stay in normal range especially in athletes with structural heart disease, but literature data imply that decreased strain values could indicate decreased function earlier than ejection fraction [26]. Based on our small cohort, highly trained athletes with definite ARVC may show good RVEF and normal global strain values, while regional strain and strain rate values are decreased.

Regional strain and strain rate of the right ventricular mid free wall are valuable discriminators even in patients with preserved RVEF and normal RV GLS. This fact highlights the significance of reporting CMR based strain parameters for differentiating athlete's heart and ARVC. Due to the moderate sensitivity our cut-off values confirms that CMR is not an appropriate first line screening method, good or excellent specificity enhances its role to prevent unnecessary disqualification because of overdiagnosing ARVC.

The major limitation of our study is the single-center nature and the limited number of participants. Additionally, our ARVC patients represent an older population compared to our athletes, although age differences may not necessarily influence our results - there have been contradictory data originating from the studies on the effect of aging on strain values $[27,28]$. Another limitation of our study are 
Table 4 Area under the ROC curves and cut-off values for optimised sensitivity and specificity

\begin{tabular}{lccccl}
\hline & Cut-off value & AUC & Sensitivity & Specificity & p \\
\hline CMR task force criteria & & & & & \\
RVEF & $\leq 45.8$ & $\mathbf{0 . 8 3 0}$ & 67.65 & 100.00 & 0.0001 \\
RVEDVi & $>150.8$ & 0.599 & 29.41 & 94.12 & NS \\
Global left and right ventricular strain values & & & & \\
LV GLS & $>-17.7$ & 0.596 & 32.35 & 94.12 & NS \\
LV GCS & $>-22.5$ & 0.643 & 38.24 & 100.00 & 0.0386 \\
LV GRS & $\leq 41.8$ & 0.607 & 41.18 & 94.12 & NS \\
RV GLS & $>-20.1$ & 0.726 & 50.00 & 97.06 & 0.0004 \\
Regional strain values of the RV free wall & & & & \\
RV basal strain & $<-35.8$ & 0.634 & 70.59 & 58.82 & NS \\
RV mid strain & $>-25.6$ & $\mathbf{0 . 7 6 7}$ & 70.59 & 82.35 & 0.0001 \\
RV apical strain & $>-23.9$ & 0.694 & 55.88 & 85.29 & 0.0042 \\
RV average strain & $>-29.4$ & $\mathbf{0 . 7 7 2}$ & 73.53 & 76.47 & 0.0001 \\
RV min strain & $>-18.1$ & $\mathbf{0 . 7 8 6}$ & 70.59 & 85.29 & 0.0001 \\
RV basal strain rate & $>-1.3$ & 0.665 & 58.82 & 85.29 & 0.0195 \\
RV mid strain rate & $>-1.4$ & 0.686 & 82.35 & 50.00 & 0.0045 \\
RV apical strain rate & $>-0.9$ & 0.606 & 38.24 & 91.18 & NS \\
RV average strain rate & $>-1.13$ & 0.665 & 52.94 & 88.24 & 0.0175 \\
RV min strain rate & $>0.8$ & 0.702 & 55.88 & 82.35 & 0.0014 \\
\hline
\end{tabular}

Parameters showing good accuracy appears in bold the gender differences between the athletes with ARVC and the other two groups. Genetic mutation screening was not routinely performed in our patient population.

\section{Conclusion}

Our study highlights that RV dilatation in healthy endurance athletes with regular and intensive training may reach the proposed Task Force criteria in almost $95 \%$. Therefore, elevated RVEDVi is an insufficient criterion for morphological diagnosis of ARVC. Besides establishing RVEF using CMR,
RV strain analysis can provide an important tool to diagnose ARVC and distinguish it from athlete's heart. CMR based regional strain and strain rate values may help to identify ARVC even in highly trained athletes with preserved RVEF and normal RV GLS. 


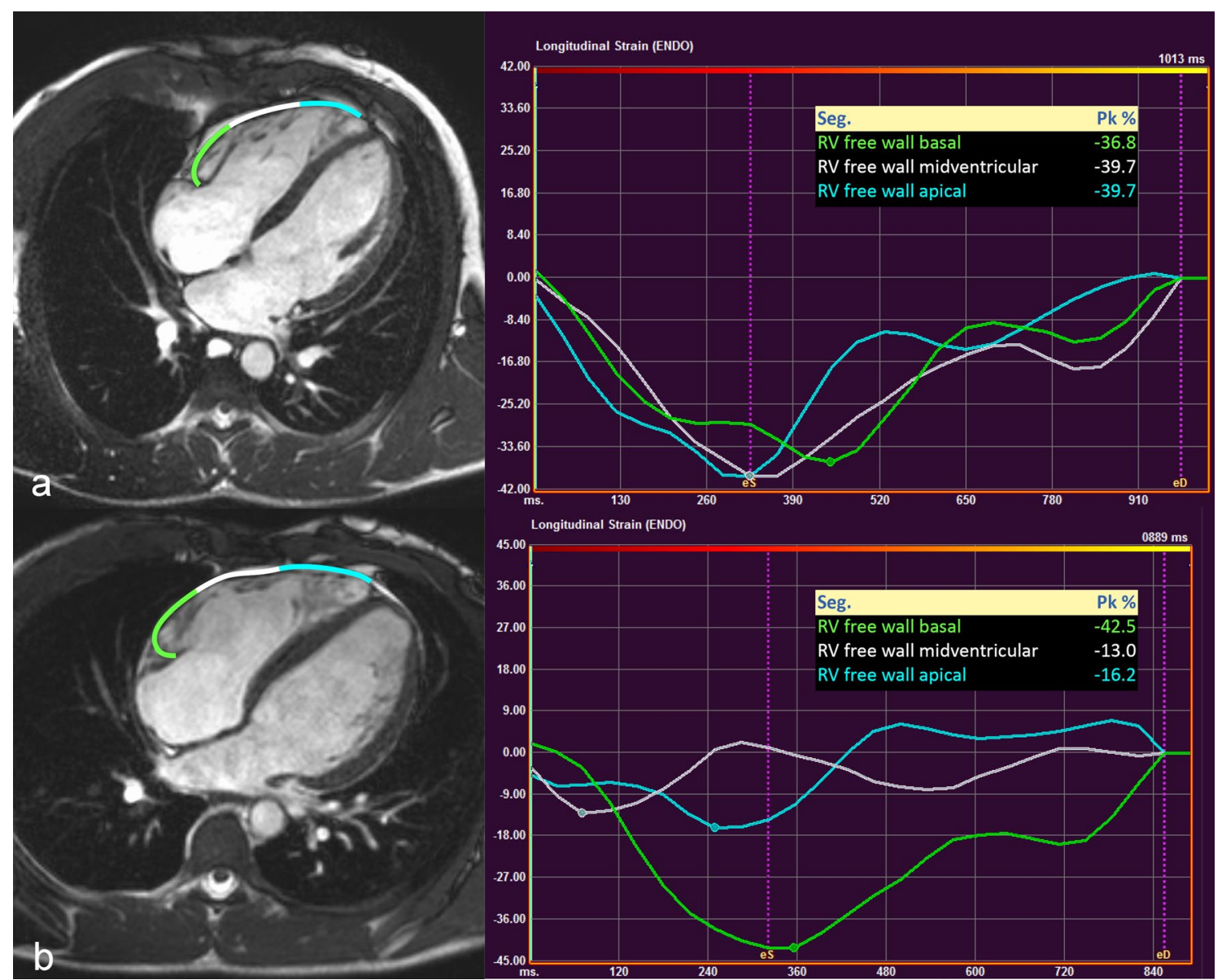

Fig. 3 Regional free RV wall strain analysis of a healthy athlete (a) and a highly trained athlete with ARVC (b). Strain curves of the athlete with ARVC represent regional RV dyssynchrony and decreased

Acknowledgements The authors would like to thank all of the patients and athletes for their participation in the study. This project was supported by a grant from the National Research, Development and Innovation Office (NKFIH) of Hungary (K 120277). Project No. NVKP_161-2016-0017 has been implemented with the support provided from the National Research, Development and Innovation Fund of Hungary, financed under the NVKP_16 funding scheme. The research was financed by the Higher Education Institutional Excellence Programme of the Ministry of Human Capacities in Hungary, within the framework of the Therapeutic Development thematic programme of the Semmelweis University.

\section{Compliance with ethical standards}

Conflict of interest The authors have nothing to declare.

Open Access This article is distributed under the terms of the Creative Commons Attribution 4.0 International License (http://creativeco mmons.org/licenses/by/4.0/), which permits unrestricted use, distribution, and reproduction in any medium, provided you give appropriate credit to the original author(s) and the source, provide a link to the Creative Commons license, and indicate if changes were made. longitudinal strain of the midventricular (white) and apical (blue) RV free wall. Segments of the RV free wall and regional strain values of these segments are presented using the same colour

\section{References}

1. D'Ascenzi F, Pisicchio C, Caselli S, Di Paolo FM, Spataro A, Pelliccia A (2017) RV remodeling in olympic athletes. JACC Cardiovasc Imaging 10(4):385-393. https://doi.org/10.1016/j. jcmg.2016.03.017

2. Corrado D, Basso C, Rizzoli G, Schiavon M, Thiene G (2003) Does sports activity enhance the risk of sudden death in adolescents and young adults? J Am Coll Cardiol 42(11):1959-1963

3. Thiene G, Nava A, Corrado D, Rossi L, Pennelli N (1988) Right ventricular cardiomyopathy and sudden death in young people. N Engl J Med 318(3):129-133. https://doi.org/10.1056/NEJM1 98801213180301

4. Marcus FI, McKenna WJ, Sherrill D, Basso C, Bauce B, Bluemke DA et al (2010) Diagnosis of arrhythmogenic right ventricular cardiomyopathy/dysplasia: proposed modification of the task force criteria. Eur Heart J 31(7):806-814. https:// doi.org/10.1093/eurheartj/ehq025

5. Bourfiss M, Vigneault DM, Aliyari Ghasebeh M, Murray B, James CA, Tichnell C et al (2017) Feature tracking CMR reveals abnormal strain in preclinical arrhythmogenic right ventricular dysplasia/cardiomyopathy: a multisoftware feasibility and clinical implementation study. J Cardiovasc Magn Reson 19(1):66. https://doi.org/10.1186/s12968-017-0380-4 
6. Prati G, Vitrella G, Allocca G, Muser D, Buttignoni SC, Piccoli $\mathrm{G}$ et al (2015) Right ventricular strain and dyssynchrony assessment in arrhythmogenic right ventricular cardiomyopathy: cardiac magnetic resonance feature-tracking study. Circ Cardiovasc Imaging 8(11):e003647. https://doi.org/10.1161/CIRCIMAGIN G.115.003647 (discussion e003647)

7. Heermann P, Hedderich DM, Paul M, Schulke C, Kroeger JR, Baessler B et al (2014) Biventricular myocardial strain analysis in patients with arrhythmogenic right ventricular cardiomyopathy (ARVC) using cardiovascular magnetic resonance feature tracking. J Cardiovasc Magn Reson 16:75. https://doi. org/10.1186/s12968-014-0075-Z

8. Vigneault DM, te Riele AS, James CA, Zimmerman SL, Selwaness M, Murray B et al (2016) Right ventricular strain by MR quantitatively identifies regional dysfunction in patients with arrhythmogenic right ventricular cardiomyopathy. J Magn Reson Imaging 43(5):1132-1139. https://doi.org/10.1002/ jmri.25068

9. Lie OH, Dejgaard LA, Saberniak J, Rootwelt C, Stokke MK, Edvardsen T et al (2018) Harmful effects of exercise intensity and exercise duration in patients with arrhythmogenic cardiomyopathy. JACC Clin Electrophysiol 4(6):744-753. https://doi. org/10.1016/j.jacep.2018.01.010

10. Wang W, Orgeron G, Tichnell C, Murray B, Crosson J, Monfredi $\mathrm{O}$ et al (2018) Impact of exercise restriction on arrhythmic risk among patients with arrhythmogenic right ventricular cardiomyopathy. J Am Heart Assoc. https://doi.org/10.1161/ JAHA.118.008843

11. Mont L, Pelliccia A, Sharma S, Biffi A, Borjesson M, Brugada Terradellas J et al (2017) Pre-participation cardiovascular evaluation for athletic participants to prevent sudden death: position paper from the EHRA and the EACPR, branches of the ESC. Endorsed by APHRS, HRS, and SOLAECE. Eur J Prev Cardiol 24(1):41-69. https://doi.org/10.1177/2047487316676042

12. Ruwald AC, Marcus F, Estes NA III, Link M, McNitt S, Polonsky B et al (2015) Association of competitive and recreational sport participation with cardiac events in patients with arrhythmogenic right ventricular cardiomyopathy: results from the North American multidisciplinary study of arrhythmogenic right ventricular cardiomyopathy. Eur Heart J 36(27):1735-1743. https://doi. org/10.1093/eurheartj/ehv110

13. Saberniak J, Hasselberg NE, Borgquist R, Platonov PG, Sarvari SI, Smith HJ et al (2014) Vigorous physical activity impairs myocardial function in patients with arrhythmogenic right ventricular cardiomyopathy and in mutation positive family members. Eur $\mathbf{J}$ Heart Fail 16(12):1337-1344. https://doi.org/10.1002/ejhf.181

14. Luijkx T, Velthuis BK, Prakken NH, Cox MG, Bots ML, Mali WP et al (2012) Impact of revised task force criteria: distinguishing the athlete's heart from ARVC/D using cardiac magnetic resonance imaging. Eur J Prev Cardiol 19(4):885-891. https://doi. org/10.1177/1741826711414215

15. Biffi A, Pelliccia A, Verdile L, Fernando F, Spataro A, Caselli $S$ et al (2002) Long-term clinical significance of frequent and complex ventricular tachyarrhythmias in trained athletes. J Am Coll Cardiol 40(3):446-452

16. Choung HYG, Vyas M, Jacoby D, West B (2017) Arrhythmogenic right ventricular cardiomyopathy (ARVC) in a young female athlete at 36 weeks gestation: a case report. Pathol Res Pract 213(10):1302-1305. https://doi.org/10.1016/j.prp.2017.07.015

17. Hedley JS, Al Mheid I, Alikhani Z, Pernetz MA, Kim JH (2017) Arrhythmogenic right ventricular cardiomyopathy in an endurance athlete presenting with ventricular tachycardia and normal right ventricular function. Tex Heart Inst J 44(4):290-293. https://doi. org/10.14503/THIJ-16-6025

18. Levine BD, Baggish AL, Kovacs RJ, Link MS, Maron MS, Mitchell JH (2015) Eligibility and disqualification recommendations for competitive athletes with cardiovascular abnormalities: task force 1: classification of sports: dynamic, static, and impact: a scientific statement from the American heart association and American college of cardiology. J Am Coll Cardiol 66(21):2350-2355. https:// doi.org/10.1016/j.jacc.2015.09.033

19. Prakken NH, Velthuis BK, Teske AJ, Mosterd A, Mali WP, Cramer MJ (2010) Cardiac MRI reference values for athletes and nonathletes corrected for body surface area, training hours/week and sex. Eur J Cardiovasc Prev Rehabil 17(2):198-203. https:// doi.org/10.1097/HJR.0b013e3283347fdb

20. Bohm P, Schneider G, Linneweber L, Rentzsch A, Kramer N, Abdul-Khaliq $\mathrm{H}$ et al (2016) Right and left ventricular function and mass in male elite master athletes: a controlled contrastenhanced cardiovascular magnetic resonance study. Circulation 133(20):1927-1935. https://doi.org/10.1161/CIRCULATIO NAHA.115.020975

21. McLeod K, Wall S, Leren IS, Saberniak J, Haugaa KH (2016) Ventricular structure in ARVC: going beyond volumes as a measure of risk. J Cardiovasc Magn Reson 18(1):73. https://doi. org/10.1186/s12968-016-0291-9

22. Haugaa KH, Basso C, Badano LP, Bucciarelli-Ducci C, Cardim N, Gaemperli O et al (2017) Comprehensive multi-modality imaging approach in arrhythmogenic cardiomyopathy - an expert consensus document of the European association of cardiovascular imaging. Eur Heart J Cardiovasc Imaging 18(3):237-253. https://doi. org/10.1093/ehjci/jew229

23. Badano LP, Kolias TJ, Muraru D, Abraham TP, Aurigemma G, Edvardsen T et al (2018) Standardization of left atrial, right ventricular, and right atrial deformation imaging using two-dimensional speckle tracking echocardiography: a consensus document of the EACVI/ASE/Industry task force to standardize deformation imaging. Eur Heart J Cardiovasc Imaging. https://doi.org/10.1093/ ehjci/jey042

24. Schuster A, Hor KN, Kowallick JT, Beerbaum P, Kutty S (2016) Cardiovascular magnetic resonance myocardial feature tracking: concepts and clinical applications. Circ Cardiovasc Imaging 9(4):e004077. https://doi.org/10.1161/CIRCIMAGING.115.00407 7

25. Oxborough D, Sharma S, Shave R, Whyte G, Birch K, Artis N et al (2012) The right ventricle of the endurance athlete: the relationship between morphology and deformation. J Am Soc Echocardiogr 25(3):263-271. https://doi.org/10.1016/j.echo.2011.11.017

26. Teske AJ, Cox MG, Te Riele AS, De Boeck BW, Doevendans PA, Hauer RN et al (2012) Early detection of regional functional abnormalities in asymptomatic ARVD/C gene carriers. J Am Soc Echocardiogr 25(9):997-1006. https://doi.org/10.1016/j. echo.2012.05.008

27. Liu B, Dardeer AM, Moody WE, Edwards NC, Hudsmith LE, Steeds RP (2018) Normal values for myocardial deformation within the right heart measured by feature-tracking cardiovascular magnetic resonance imaging. Int J Cardiol 252:220-223. https:// doi.org/10.1016/j.ijcard.2017.10.106

28. Taylor RJ, Moody WE, Umar F, Edwards NC, Taylor TJ, Stegemann B et al (2015) Myocardial strain measurement with feature-tracking cardiovascular magnetic resonance: normal values. Eur Heart J Cardiovasc Imaging 16(8):871-881. https://doi. org/10.1093/ehjci/jev006 